\begin{tabular}{|c|c|}
\hline & $\begin{array}{l}\text { International Journal of Trend in Scientific } \\
\text { Research and Development (IJTSRD) }\end{array}$ \\
\hline 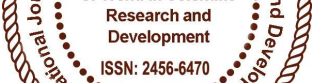 & International Open Access Journal \\
\hline 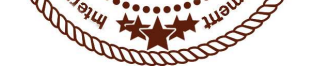 & ISSN No: 2456 - 6470 | www.ijtsrd.com | Volume - 2 | Issue - 2 \\
\hline
\end{tabular}

\title{
Adsorption of Acidic pollutants from Water using Biosorbents
}

\author{
Syeda Sameena Aziz \\ Dept. of Chemistry, Anwarul-uloom College, \\ Mallepally, Hyderabad, Telangana State, India
}

\author{
Abdul Razzak \\ Dept. of Chemistry, Anwarul-uloom College, \\ Mallepally, Hyderabad, Telangana State, India
}

\section{ABSTRACT}

A huge amount of waste is generated from the industries which cause the pollution of water; this waste is generated by the industries in large quantities. Acids are one such of a waste generated by these industries in the water bodies and causes an adverse impact on the aquatic ecosystems and inturn causes an negative impact on the human population and because of the harmful effects caused by these acids there is a need for the removal of these acidic pollutants from our water bodies. As these acids are water soluble $^{[1]}$ and colorless we need a technique to separate these acidic pollutants from water and at the same time determine their concentrations in water. So, in the present investigation we have used the Biosorption ${ }^{[2]}$ for the removal of the acidic pollutants like Acetic, Oxalic and Phosphoric acids and the method of determination of concentration of these acids is through simple volumetric analysis .For this biosorption technique the selection of various biosorbents were done and it was noticed that the sawdust along with mango leaves prove to be an effective mixture of biosorbent for the removal of the acidic pollutants from water. The Freundlich and Langmuir adsorption isotherms have been verified by the experimental data. The Biosorption studies were done at room temperature.

Keywords: Adsorption, Adsorption isotherms, Biosorption, Volumetric analysis, Biosorbents, Sawdust, Mixture of Biosorbents

\section{Introduction:}

Industries of the various fields are releasing acids as their waste products into the water bodies which are causing the pollution of various water bodies ${ }^{[3]}$. In the group of acidic pollutants the main concerned is towards Acetic, Oxalic and Phosphoric acids, as these acids are emitted out as waste in large quantities. These acids have very hazardous properties and these acids are very hard to remove as they are easily soluble in water ${ }^{[4]}$.

The Acetic Acid is generated as the waste product of the Pharma industry as a waste product and is emitted out in the water bodies; this disturbs the aquatic ecosystems by causing some alterations in the aquatic organisms which inturn depletes the aquatic species. Similarly Oxalic Acid is a waste product of the Agricultural Industry where it is used in excess in the man-made fertilizers. This reaches the water bodies through soil erosion and forms various compounds with water which causes a health hazard to both aquatic and human life. Phosphoric Acid is generated as a waste product from various chemical industries, this acid when reaches the water bodies; increases the contamination potential of water and hence causes an adverse affect on the aquatic life and inturn causing a negative effect on human beings.

There is a growing threat for human life by these acidic pollutants and hence there is a need to remove these pollutants from water ${ }^{[5]}$. As these pollutants are miscible in water and colorless in nature, the method of separation of these acidic pollutants is through 
Biosorption techniques as the adsorbent used here is naturally available and not synthetic ${ }^{[6]}$. These days the biosorbents are making an attractive mark as these are easily available and are of less cost when compared to the synthetic adsorbents. Biosorbents are the waste products of materials which are abundant in nature. Saw dust and the mango leaves in nature acts as an effective biosorbent because this saw dust contains the powder forms of various barks of trees and the mango leaves are found in abundant in the mango gardens. Solid waste management is also done by these biosorption techniques as these biosorbents are in nature the waste products of the environment ${ }^{[7]}$.

In the present study the identification of a mixture saw dust and mango leaves as a biosorbent is made through the adsorption studies of Acetic, Oxalic and Phosphoric acid by this mixture of saw dust and mango leaves as the biosorbent. The experimental data is verified by the Freundlich and Langmuir adsorption isotherms and the studies were carried out at room temperature.

\section{Materials and Method:}

The adsorbates taken here are the Acetic, Oxalic and Phosphoric acids. These acids were taken separately in $0.5 \mathrm{M}$ aqueous solutions. This is prepared as the stock solution. The stock solutions of the different acids are made into different dilutions and are taken up for the adsorption studies.

Saw dust was collected from a local saw mill. Mango leaves were collected from the neighborhood. The saw dust and mango leaves were washed separately burnt in the muffle furnace at $200^{\circ} \mathrm{C}$ and were sieved for uniformity and stored in air tight containers. The adsorption is carried out on acids which are water soluble and colorless; the determination of the concentration of the acid is done through the mechanism of simple acid-base titration ${ }^{[8]}$. The indicator used in these titrations is the Phenolphthalein indicator.

\section{Experiment:}

The saw dust and the mango leaves stored were taken in separate china dishes and were heated up in a muffle furnace at $200^{\circ} \mathrm{C}$ and the residue obtained from this process is the activated carbon of the saw dust and mango leaves ${ }^{[9]}$. This is used up in the adsorption studies of Acetic, Oxalic and Phosphoric acids. This saw dust and the mango leaves were mixed in equal proportions and the mixture was taken in same amounts for the different adsorbate. For Acetic, Oxalic and Phosphoric acids the mixture of the saw dust and mango leaves were taken in $0.6 \mathrm{~g} / 100 \mathrm{ml}$. After a time period of $24 \mathrm{hrs}$ these respective dilutions were taken up for the adsorption studies which were carried out through acid-base titration. In this $0.1 \mathrm{M}$ sodium hydroxide is taken in a burette and $10 \mathrm{ml}$ of the filtered dilutions are taken in a conical flask. 2-3 drops of Phenolphthalein indicator was added. Now the sodium hydroxide is allowed to enter the conical flask drop wise and the burette readings were noted for each dilution as the base neutralizes the acid present in the conical flask. This is noted by the appearance of pink color in the conical flask marking the completion of the neutralization reaction.

\section{Results and Discussion:}

The study of the adsorption by the mixture of saw dust and mango leaves against Acetic, Oxalic and Phosphoric acids has been studied by using the Freundlich and Langmuir adsorption isotherms. The Freundlich and Langmuir plots for these acids are shown in fig 1, fig 2 , and fig 3 respectively.

The Freundlich adsorption isotherm equation is $\log \frac{x}{M}=\log k+\frac{1}{n} \times \log C_{e}$

[10]

The Langmuir adsorption isotherm is valid for the adsorption of monolayered nature onto a surface with a finite number of identical sites. The Langmuir adsorption isotherm equation is

$\frac{C_{e}}{x / M}=\frac{1}{k_{1} \times k_{2}}+\frac{C_{e}}{k_{2}}[10]$

Where $\mathrm{k}_{1}$ and $\mathrm{k}_{2}$ are Langmuir constants. The Freundlich adsorption isotherm using the mixture of saw dust and mango leaves for the removal of Acetic, Oxalic and Phosphoric acids yielded a straight line with an intercept. The graphs are represented in the respected figures as discussed earlier. The ' $\log \mathrm{k}$ ' and ' $n$ ' values are noted in table 1. The Langmuir adsorption isotherm which is the graph between $\mathrm{Ce} / \mathrm{x} / \mathrm{m}$ which is on the $\mathrm{y}$-axis and Ce which is on $\mathrm{x}$ axis yielded a straight line with an intercept which is in accordance to the Langmuir adsorption isotherm. The Langmuir constants $\mathrm{k}_{1}$ and $\mathrm{k}_{2}$ of Acetic, Oxalic and Phosphoric acids were calculated and are listed in table 2 . 

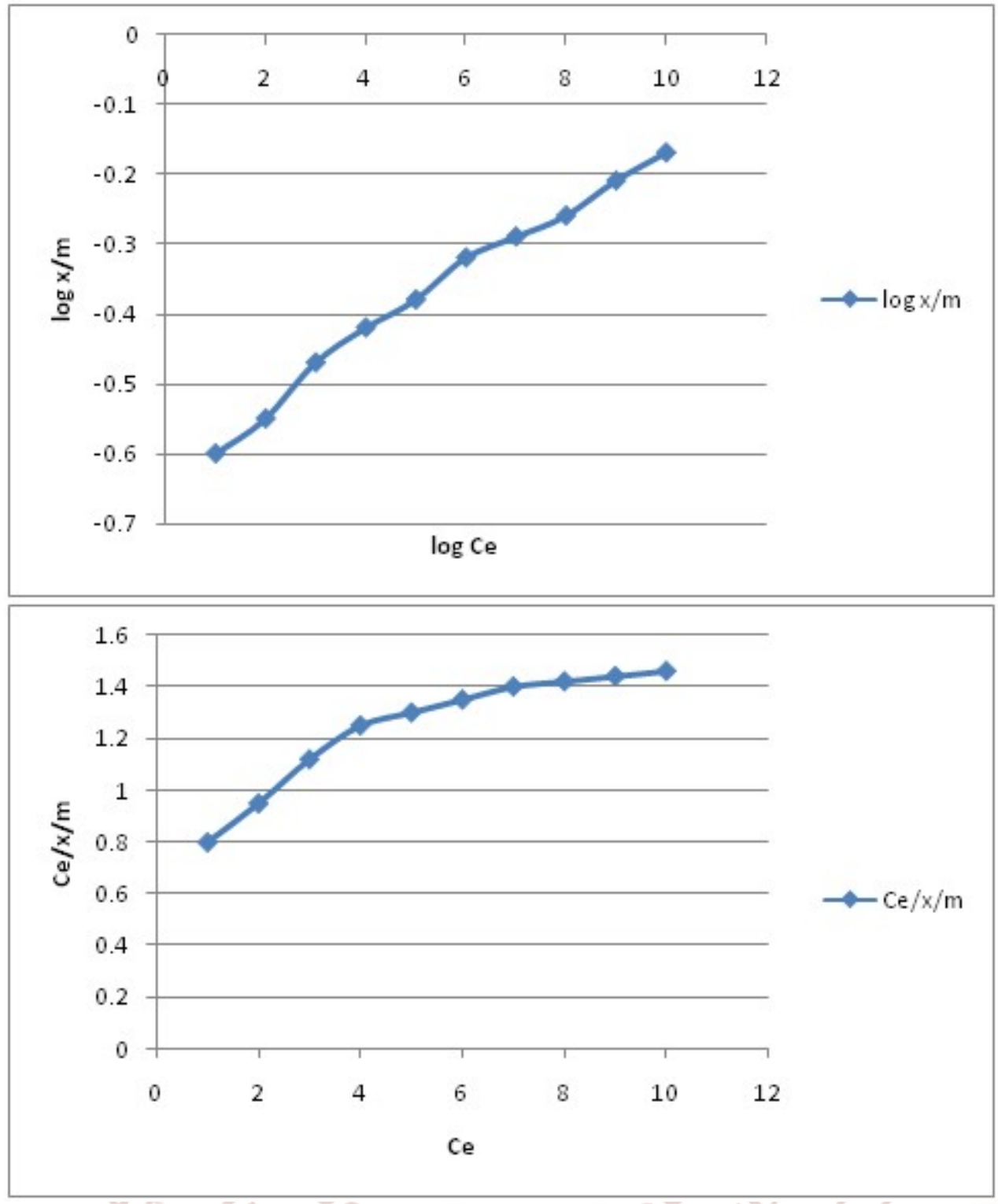

Fig 1: Freundlich and Langmuir Plot for Acetic Acid with 0.6g saw dust and mango leaves mixture

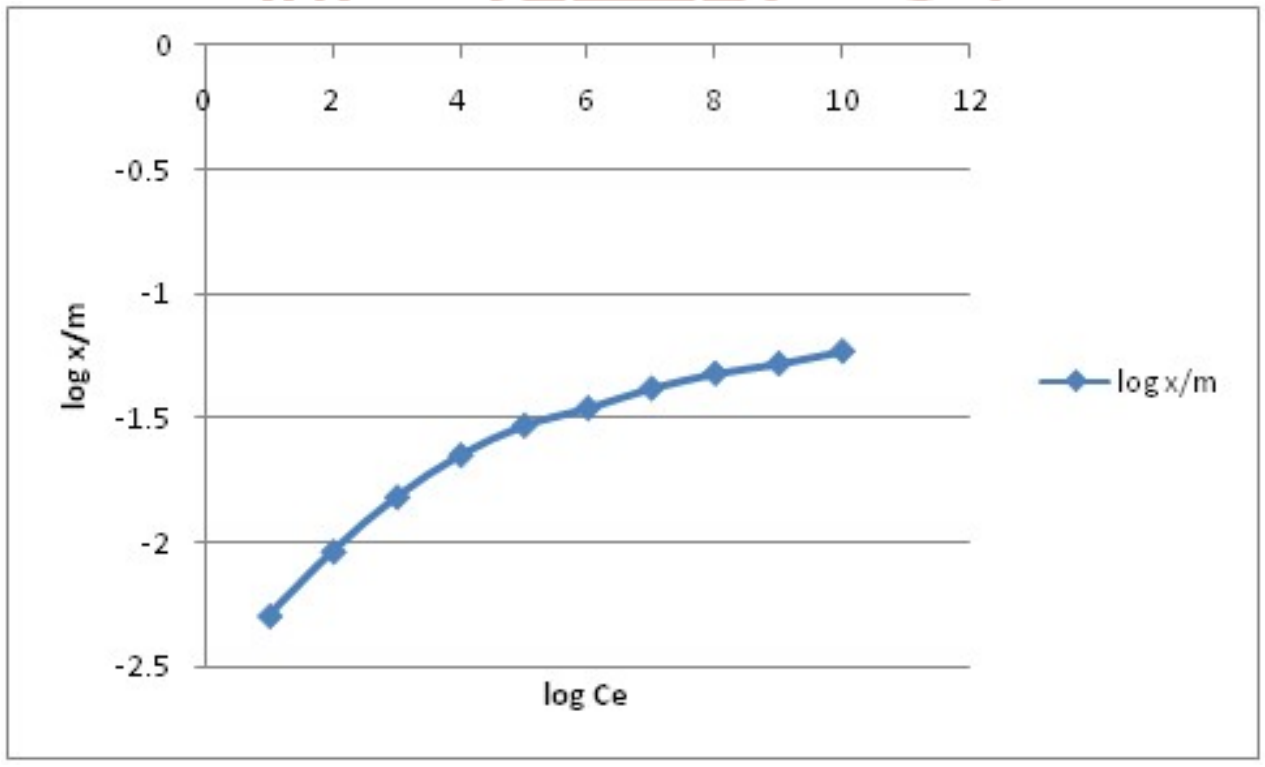

@ IJTSRD | Available Online@www.ijtsrd.com | Volume-2 | Issue-2 | Jan-Feb 2018 


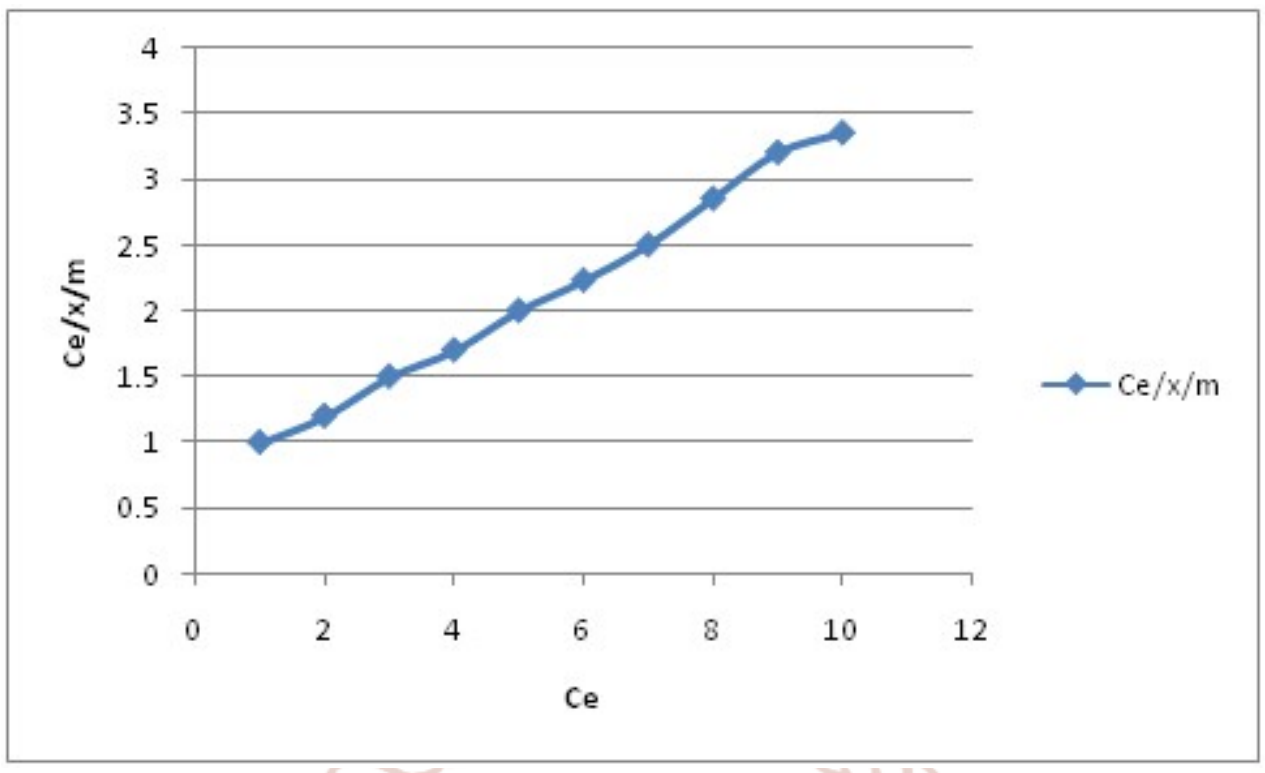

Fig 2: Freundlich and Langmuir Plot for Oxalic Acid with 0.6g saw dust and mango leaves mixture

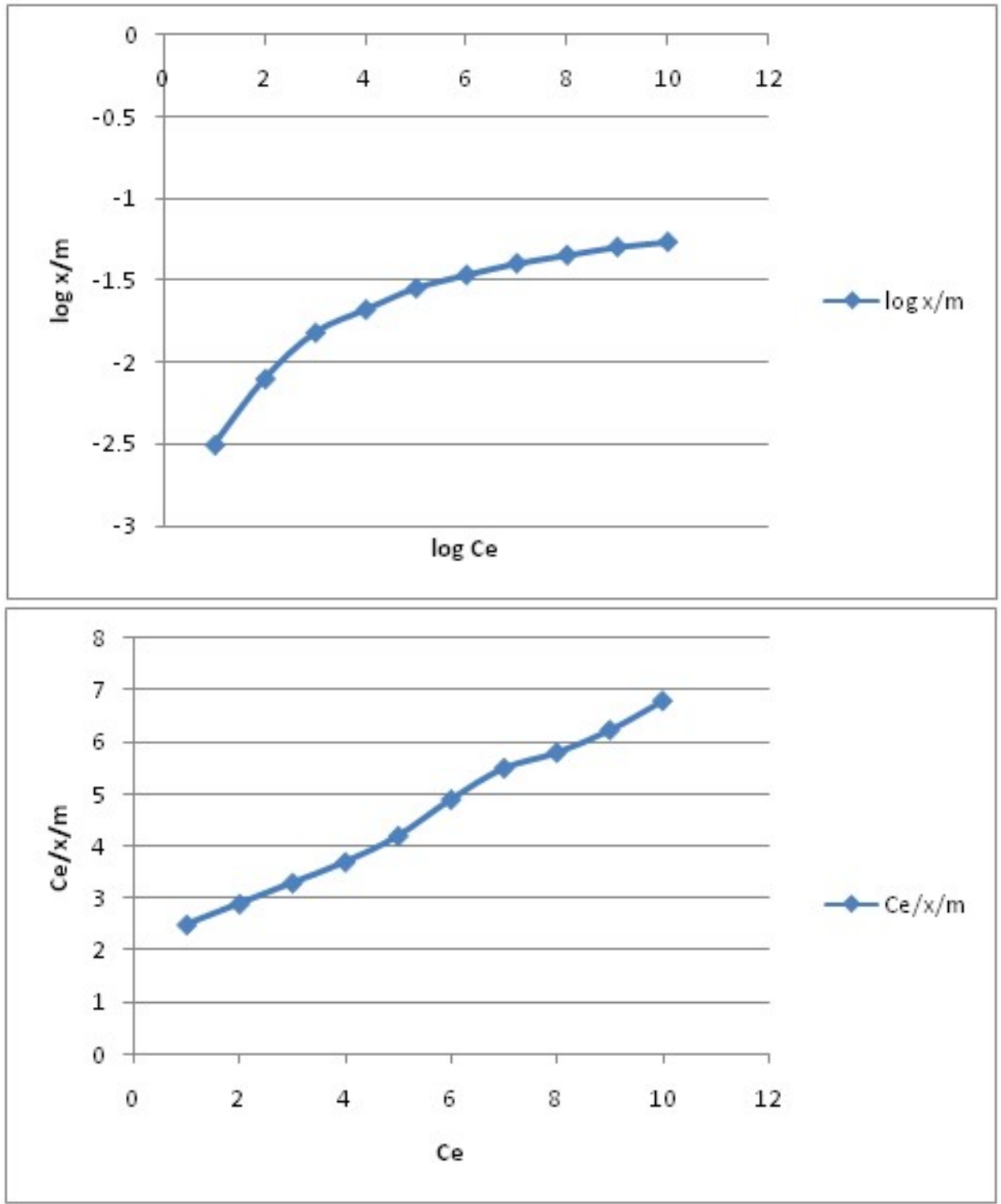

Fig 3: Freundlich and Langmuir Plot for Phosphoric Acid with 0.6g saw dust and mango leaves mixture 
Table 1: $\log k$ and $n$ values obtained from the Freundlich plot of different acids

\begin{tabular}{|l|l|l|}
\hline Acid & Log k & n \\
\hline Acetic Acid & -0.7 & 0.065 \\
\hline Oxalic Acid & -2.5 & 0.095 \\
\hline Phosphoric Acid & -3 & 0.21 \\
\hline
\end{tabular}

Table 2: $k_{1}$ and $k_{2}$ values obtained from the Langmuir plot of different acids

\begin{tabular}{|l|l|l|}
\hline Acid & $\mathbf{k}_{1}$ & $\mathbf{k}_{2}$ \\
\hline Acetic Acid & 0.26 & 6.25 \\
\hline Oxalic Acid & 0.31 & 4 \\
\hline $\begin{array}{l}\text { Phosphoric } \\
\text { Acid }\end{array}$ & 0.2 & 2.5 \\
\hline
\end{tabular}

\section{Conclusion:}

The results obtained from the studies of the adsorption characteristics of the mixture of saw dust and mango leaves are in agreement with the Freundlich and Langmuir adsorption isotherms. The values obtained from the Langmuir plots suggest that the mixture of saw dust and mango leaves has a great adsorption potential for Acetic, Oxalic and Phosphoric Acid and the maximum adsorption potential is shown by Acetic acid. So we found that the mixture of saw dust and mango leaves is an easily available and cost-effective biosorbent for the removal of Acids.

\section{References:}

1. K. S. Mundhe, Adsorption Study of Acetic Acid using Low Cost Biosorbent, Int.J.Curr.Microbiol.App.Sci (2015) 4(12): 66-72.

2. Das Kumar M. and Attar J.S., 2011. Comparative study of batch adsorption fluoride using commercial and natural adsorbent. Res.J.Chem.Sci, 1(7), 68-75.

3. Mohan D., Singh K.P., 2002. Singleand multicomponent adsorption of cadmium and zinc using activated carbon derived from bagasse an agricultural waste. Wat. Res., 36, 2304-2318.

4. Ana Fernando et al, Production of Biosorbents from Waste Olive Cake and Its Adsorption Characteristics for $\mathrm{Zn} 2+$ Ion. Sustainability 2009, 1, 277-297; doi:10.3390/su1020277.

5. T. MURUGAN, A. GANAPATHI and R. VALLIAPPAN, Removal of Dyes from Aqueous
Solution by Adsorption on Biomass of Mango (Mangifera Indica) Leaves, ISSN: 0973-4945; CODEN ECJHAO E-Journal of Chemistry 2010, 7(3), 669-676.

6. The free dictionary by Farlax

7. Biosorption- An eco friendly technique for removal of heavy metals Sasmita sabat et al, Indian Journal of Applied Research Vol-2 Issue: 3 Dec- 2012

8. www.fpham.uniba.sk/Excersise5

9. National pollutant Inventory (NPI), Australia

10. Advanced Physical Chemistry by Gurtu, Snehi; Reprint of $7^{\text {th }}$ Edition (2005) pg no, 492-496. 